\title{
A case study on learning basic logical competencies when utilising technologies and real-world objects
}

\author{
Robert Weinhandl $^{1}$ (D) $\cdot$ Tony Houghton ${ }^{1} \cdot$ Zsolt Lavicza $^{1}$
}

Received: 23 May 2020 / Accepted: 7 July 2020 / Published online: 12 July 2020

(C) The Author(s) 2020

\begin{abstract}
In our technological age, many technologies and real-world objects communicate with each other or partly merge. However, this combination of technologies and real-world objects has not yet found its way into everyday teaching practices in schools to any great extent. To investigate the possibilities of combining technologies and real-world objects in mathematics classes, we conducted an exploratory educational study with 47 students. Analysing students' data using the principles of grounded theory demonstrated that for students in our study (A) using open tasks with multiple solutions, (B) immediate feedback and $(\mathrm{C})$ novelty effects in the learning process, are essential to design mathematics learning environments with combining technologies and realworld objects when learning basic logical operations.
\end{abstract}

Keywords Basic logical operations · Hands-on learning · Learning logical competencies · Technology-enhanced learning environments

\section{Introduction}

New technologies have been having a significant impact on society in recent years. As schools and educational institutions are part of society, new technologies also have a significant impact on teaching and learning in schools, but this often happens some years later than in other fields such as business or science (Samuelsson 2006). Currently, we are experiencing not only the proliferation of digital technologies, but also their combination and communicating with everyday objects. Combining digital technologies, learning and real-world objects can be found slowly growing also in mathematics lessons. In their studies, Borba et al. (2016) and Pierce and Stacey (2011) summarise that using modern technologies in mathematics learning could facilitate

Robert Weinhandl

robert.weinhandl@gmail.com

1 Johannes Kepler University, Linz, Austria 
students in mathematising real-world problems. Most combinations of digital technologies, mathematics learning and real-world objects often focus on geometry.

In our educational case study, we explored how the combination of selected technologies and real-world objects could be linked to promote mathematics learning beyond geometry. To investigate how real-world objects and technologies could be linked to enhance mathematics learning beyond geometry, we decided to use Logifaces (real-world objects) and MS Excel (technology) to learn logical operations.

\section{Theoretical background}

Pseudo-realistic problems are those tasks which simplify real-world phenomena for teaching and learning purposes. Carreira and Baioa (2018) summarise that pseudorealistic problems should often trigger mathematics learning. However, pseudo-realistic problems might reduce and simplify real-world situations too much, resulting in students not using their knowledge of the real-world when learning. For this reason, Heck (2010) recommends placing real-world problems at the centre of mathematics learning. By treating real-world problems, students can learn in educational settings like real scientists. In this context, learning as real scientists is closely linked to learning by doing.

\subsection{Combining basic logical competencies and technologies}

In our educational case study, the real-world problem was the matching of Logifacesstones (see Fig. 1 left). Students' task was to determine whether or not two stones could form a pair so that their joint surface has no steps and form a smooth surface (see Fig. 1 right). To investigate whether or not two Logifaces-stones form a pair, students of our study also had to use MS Excel and develop a programme to investigate whether or not two Logifaces-stones can form a smooth surface. When developing this MS Excel program, students also had to use basic logical operations. We decided to use MS Excel because Tabach et al. (2006) showed in their study that students could achieve considerable cognitive growth in learning mathematics by using MS Excel.

Using technologies in our educational case study followed the well-known work of Noss and Hoyles (2010) and Noss et al. (1997) who were already able to illustrate at the end of the last Century that educational technologies facilitate turning learning environments into laboratories. Such technology-enhanced lab-like learning environments could enable students to explore mathematical content with experimentation and with
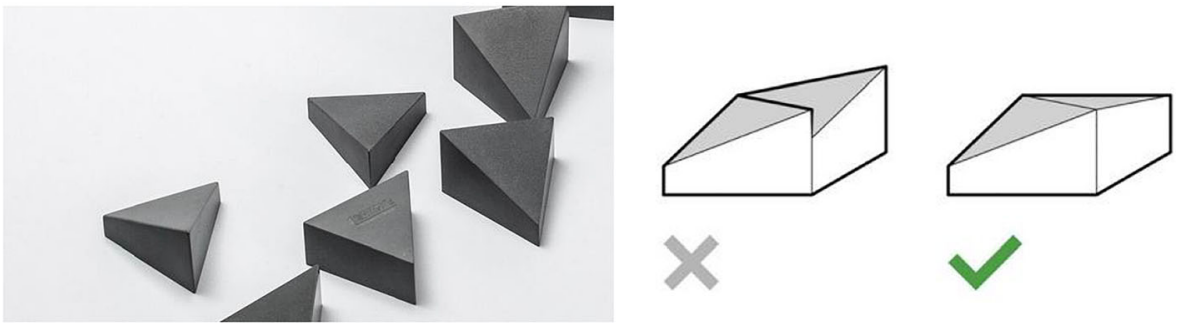

Fig. 1 Logifaces-stones and how to match them 
their creative approaches. As educational technologies and related pedagogies have been extensively studied and significantly developed over the past 20 years and using technologies has been simplified since the late 1990s, we assume that nowadays, it is easier to develop promising technology-enhanced lab-like learning environments.

\subsection{Mathematical content of our study}

The mathematical content we aimed students discover in a technology-enhanced learning environment in our educational case study was basic logical operations. According to Henderson (2014), it is basic logic and conceptual problem solving that should be considered early in students' educational careers in mathematics teaching. As logical operations and using technologies are central to the field of computing and computational thinking, and thus becoming always more relevant in our digital age, high quality teaching on logical operations is a key element for post- secondary education and professional life of today's secondary school students. In Austria, the country where our educational case study was conducted, and in the German-speaking countries in general, this relevance of basis logic is particularly evident. Here, basic knowledge of logic and logical operations is not only crucial in mathematics, science and computing but is found in many other university curricula and vocational fields that are not per se associated with mathematics. For example, basic logic is a compulsory part of the curriculum in economics (https://friedolin.uni-jena. de/qisserver/rds; jsessionid=D6FF041661EAC277A63205E55219A71A.worker32 ?state $=$ wtree $\&$ search $=1 \& \operatorname{root} 120192=473737 \% 7 \mathrm{C} 472876 \% 7 \mathrm{C} 472594 \% 7 \mathrm{C} 472149$ $\% 7 C 472583 \&$ trex=step), in digital communication and marketing (https://online.fhwien.ac.at/fhwienonline/wbLv.wbShowLVDetail?pStpSpNr=230291\&pSpracheNr=) or linguistics (https://hpsg.hu-berlin.de/ stefan/Lehre/S2012/as-logik.html). Since basic logical knowledge is part of both the curricula of mathematical related degree programmes and many curricula of other programmes, students should develop a logical knowledge framework already in secondary schools. As logical foundations are only part of the curriculum in the 9th grade (AHS) in Austria, high quality and engaging teaching on this topic should be of particular importance.

\subsection{Using technologies for learning logical foundations}

Considering technologies in our educational case study on learning logical foundations is supported by several educational studies which have showed that a technologyenhanced learning environment could be a fruitful setting for learning logical foundations. For example, in an educational case study, Kabaca (2013) used technologies to learn logical operations AND and OR. By combining technologies and logical operations, a holistic learning environment could be developed in which technologies made it possible to investigate whether the solutions developed are correct. Furthermore, Celedón-Pattichis et al. (2013) illustrated in their educational study that logical operations and technologies are a combination that could also inspire underrepresented groups for STEM. In our case, students with a migrant and a low socio-economic background form the group of underrepresented students.

For our educational case study, both the findings of Kabaca (2013) and CeledónPattichis et al. (2013) are essential as on the one hand, students in our educational 
experiment should be enabled to use technologies to investigate whether their considerations regarding the matching of Logifaces-stones are correct - i.e. that two Logifaces-stones form a smooth surface. On the other hand, our educational case study aims to investigate a technology-enhanced learning environment that should motivate many students to work with and learn logical operations. The fact that both mathematically interested as well as less interested students might need logical operations at a later stage in their educational careers or in their professional life justifies the focus of our educational case study on learning logical operations in a technology-enhanced learning environment using real-world objects.

Another argument for combining technologies and explorative learning is that this approach to learning could also promote students' meta-competencies such as linguistic or social competencies. Clarkson (2003) was able to illustrate in her study that learning logic and also logical operators can also enhance students' language skills. The fact that students should first organise internal logical thinking and then communicate through language to their classmates or teachers supports the learning of logic and logical operators. To promote this meta-competence in our educational case study, students worked in groups of two or three.

\subsection{Research goal and question of our study}

Since our education case study was very limited in time, we could not focus on opportunities for potential learning gains for the students or compare the design of our techno-logical learning environment with other learning environments. Instead, the goal of our education case study was to investigate how real-world objects and technologies should be linked in mathematics learning to motivate students. This focus on students' motivation when learning basic logical competencies led us to the research question:

Which design elements of a learning environment where real-world objects and using technologies are linked are essential for students to learn basic logical competencies?

\section{Our educational case study}

To investigate which design elements are essential for students when learning basic logical competencies in a learning environment in which real-world objects and technologies are linked, we conducted our educational case study in a Vienna secondary school located in the city centre. In defining basic logical competencies in our study, we have used the definition of mathematical competency by Niss and Højgaard (2019) as a guideline. Consequently, we interpret basic logical competencies as the insightful readiness of a student to react appropriately to a specific type of mathematical-logical challenge in given situations.

\subsection{The participants of our study}

Since the distance from the school to the students' home is a central factor in the admission of students to schools, it is assumed that the majority of our student 
participants live close to the city centre and have high socio-economic background as the residential area near the centre is rather expensive. The high socio-economic background of students lead to the assumption that students are familiar with working and learning with technologies in their homes, as opposed to using the technologies for leisure without learning support. The socio-economic gradient of the Pisa study (OECD 2015) also supported this assumption. Following the socio-economic gradient, there is a positive correlation between economic and social status on the one hand and the competence levels achieved by students in the fields of science and technologies on the other hand.

Three groups of learners with a total of 47 students participated in our educational case study. The learners attended 9th grade and were between 13 and 15 years old. Our educational case study undertook four lessons per group - two double lessons each. In the teaching units, students formed groups of two or three. Each group of two or three had a Logifaces set with 16 stones and a computer with Internet access.

\subsection{The implementation of our study}

A young teacher led the units, and a researcher was present in each unit. The researcher observed the learning activities of the students and took notes of the lessons, and at the same time offered help if the students had problems. In this support of the students, the researcher also conducted mini-interviews with the students to discover what was causing problems. After each double lesson, written feedback was collected from all students. When giving written feedback, students were also asked to record their satisfaction or dissatisfaction with the design elements of the lesson. Students were asked to pay particular attention to interaction with classmates and their teachers, task communication, task design and teacher expectations.

\section{Methodological framework}

To identify which design elements could be relevant to students when learning basic logical competencies in a technology-enhanced and real-world object based learning environment, we conducted an educational case study.

\subsection{Using case study principles to reach our research goal}

Since using case studies has a long tradition in mathematics education research in examining students' solution processes and methods (e.g. Cobb 1986), this research method should also be appropriate for our study. Furthermore, as case studies can be used not only to investigate solution processes and methods in problem-solving but also to explore students' emotions when solving problems in mathematics classrooms (Eynde and Hannula 2006), using case study principles should provide valuable results for our research aims. Our study focused on students solving a particular problem (developing an MS Excel program to solve the Logifaces problem) and our research goal was to explore which design elements could be relevant for students in technology-enhanced and real-world object based learning environments. 
According to Cohen et al. (2007), case studies require a clearly defined limited system of real people in real situations experiencing a specified intervention. This limited system of real people in real situations should extend the understanding of concrete ideas and interventions beyond abstract theories. In this study, the limited system was defined as three groups of students throughout four teaching units. The situation to be investigated was defined as the students of these three groups, or more precisely students' needs and requirements concerning a technology-enhanced learning environment based on real-world objects when learning basic logical competencies. The intervention included basic logical competencies were learned by students using Logifaces-stones and MS Excel.

According to the work of Yin (1984), our educational case study can be characterised as an explorative case study. The explorative character of our educational case study is because our study aims to develop hypotheses regarding design elements of learning environments in which real-world objects and technologies are linked. According to Cohen et al. (2007), among others, participatory observations or postobservation recordings are data collection methods that generally apply to case studies and are specifically appropriate for our case. Participatory observations were selected as the data collection instrument because a researcher was present in all teaching units and also interacted with the students when needed. The interactions of the researcher with the students also resulted in ongoing mini-interviews (Bakker and van Eerde 2015). The mini-interviews always lasted less than $3 \mathrm{~min}$ and were intended to help clarify why students encountered difficulties. The researcher made observational recordings immediately after the occurrence of any phenomena or after conducting mini-interviews. The data collected during the lessons were supplemented with final written feedback from students after each double lesson. According to Kane and Staiger (2012), collecting supplementary observation data through student feedback should lead to an increase in educational quality. Written feedback was chosen as a data collection tool to gather feedback from all students and to make it clear that their feedback could not be traced back. By making written feedback untraceable, it could be expected that the honesty of student's feedback was possibly increased.

\subsection{Using grounded theory approaches when collecting and evaluating research data}

When collecting and evaluating research data, we applied techniques and principles of grounded theory approaches (GTA). In our study, we followed the constructivist interpretation of GTA (Charmaz 2006) and a GTA interpretation according to Strauss and Corbin (Khan 2014). A constructivist interpretation of GTA and a GTA interpretation according to Strauss and Corbin means, on the one hand, that the previous knowledge of researchers and the current scientific body of knowledge should be included in the development of theories and hypotheses. On the other hand, this interpretation of a GTA follows that any hypothesis or theory developed in the course of research depends on the perspectives of researchers and cases under investigation.

This constructivist interpretation of GTA was particularly relevant to our exploratory educational case study, as, on the one hand, the researchers could not be described as neutral, as they sometimes took on participating and supporting roles. On the other hand, it must be assumed that theories and hypotheses on design elements of 
technology-enhanced and real-world object based learning environments developed in our exploratory education case study would have been different if our study had been conducted with other classes, at a different time, or at other schools. According to Cohen et al. (2007), results or hypotheses that depend on the framework conditions of a study are a specific feature of case studies. However, if the conditions and frameworks of the study or case are described in detail, theories or hypotheses developed in a case study can be applied to similar cases, phenomena or situations.

\subsection{Coding techniques of grounded theory approaches}

In analysing the research data and developing theories and hypotheses, we have followed a four-part approach, namely: 1) screening of new data, 2) open coding, 3) axial coding, and 4) selective coding.

We followed Ritchie's (2012) approach to initially view the new data. Initially viewing new data means that, in a first step, all researchers read the newly collected raw data. This repeated reading of the raw data was intended to give all researchers an overview of the current status of our educational case study and to be able to derive initial topics from the raw data. In the next step, the newly collected raw data were transcribed and then coded using a QDA software. Our approach to coding is based on the theoretical guidelines and practical applications of Breuer et al. (2009), Charmaz (2006) and Mey and Mruck (2011).

In the first phase of coding, we applied the techniques of open coding. The goal of open coding is to break up the collected data. To break up the collected data, we asked the questions what, how and why. The resulting first open codes were then grouped according to similar characteristics and definitions and provided with new keywords. This grouping of first open codes resulted in open codes of a higher degree of abstraction (see Table 1, columns 1 and 2).

Table 1 Selection of first and grouped open Codes as well as Core Categories

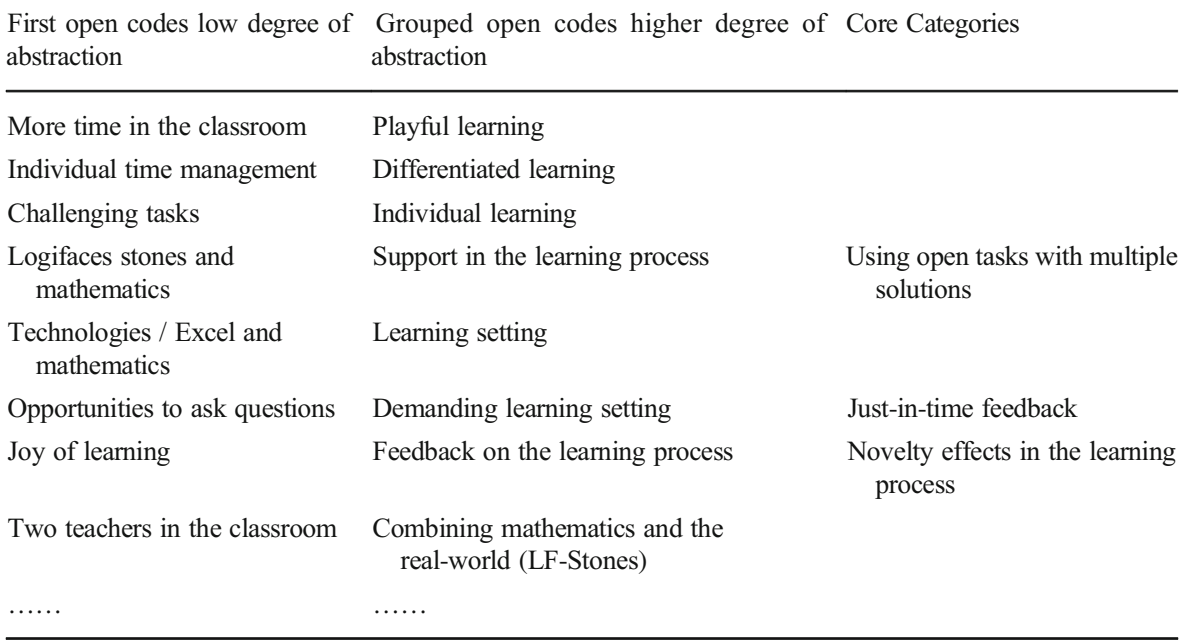


The open codes of a higher degree of abstraction were then used for axial coding. By coding open codes axially, a synthesis of the research data should be achieved again. In axial coding, open codes were grouped around a central open code (phenomenon) according to causes, activities and consequences (see Fig. 2). The open codes of the area of activities were then grouped and used as categories for selective coding. For selective coding, these categories were linked, and dependencies were identified. Identifying dependencies allowed us to develop the design elements relevant for students in terms of technologyenhanced and real-world object based learning environments for learning basic logical competencies core categories: (A) Using open tasks with multiple solutions, (B) Just-in-time feedback and (C) Novelty effects in the learning process.

Student quotes given in the section Results have been translated from German to English by us. Individual student quotes were accompanied by information whether this feedback was collected via written feedback [F] or mini-interview [I]. If feedback was collected via mini-interviews, the composition of the student group in terms of gender is also given. Here, $g$ stands for girl and $b$ for boy.

\section{Results}

Examining and analysing students' feedback to explore which design elements could be relevant when learning basic logical competencies in a learning environment where real-world objects and technologies are combined, demonstrated that A) Using open tasks with multiple solutions, B) Just-in-time feedback and C) Novelty effects in the learning process are central to students in our exploratory educational case study.

In developing the design elements of the learning environment that are central to students in our study, we did not focus on the feedback related to learning environments per se - i.e. combining technologies, using Logifaces and the intended learning of mathematics. Instead, we focused on the design elements that are central to students in such a learning environment. As the design elements central to students, we qualified those student feedbacks which could be central to students' learning or motivation, and which could support or hinder learning processes.



Combining mathematics and the real-world

Classmates as feedback-providers Feedback via technologies

Fig. 2 Prototypical process of axial coding 


\subsection{Using open tasks with multiple solutions}

A key design element for students in our exploratory educational case study was that students were able to take their learning paths in solving the problem, using their strategies. The students described the associated thinking and experimenting with their strategies or solutions as very motivating.

[F] It was good that you were able to work at your own pace and that you could work on your own idea and not just have to meet specifications.

[I, b-b-b] The fact that you can or have to think for yourself before working is really good.

In this process of learning, students described the task as a brainteaser rather than a classical mathematics task. According to the teacher's feedback, working on this brainteaser activated students much more during lessons than usual. In this context, the teacher mentioned that a high involvement could be observed in mathematical high-achievers as well as in mathematical low-achievers. An increase in activity and motivation of otherwise mathematically below average successful students is reflected in the following quote.

[I, b-b] It is really cool that we can learn and do brainteasers at the same time.

[F] I liked the fact that we were able to do more tinkering and puzzling around in the classroom than just learning normally in class.

When working on open-tasks with multiple solutions, it was positive for students that new mathematical or technological knowledge or competencies could be associated with achieving a concrete goal. Students emphasised that it was positive that only those new concepts were learned that could be used immediately when utilising a new solution strategy.

[I, g-g] We learn exactly just the things we need to solve the problem - we would not have learned these things otherwise, would we?

A key design element for students in our exploratory educational case study was that tasks were open-ended and there were several possible solutions. Achieving these open tasks was described by students as a brainteaser rather than an everyday mathematics lesson. When processing these brainteasers, it was crucial for the students that only those new concepts were introduced that were needed in the specific case.

\subsection{Just-in-time feedback}

When experimenting with Logifaces stones and Excel, it was vital for students of our study that they received immediate feedback or knew that they could get feedback at any time. Students emphasised that they found it enjoyable that a teacher and another person they could ask were present in all lessons.

[F] A good thing about the lessons was that you could always ask the teacher or the other person if your concept is right and what the commands are to realise your concept. 
In addition to teachers' feedback, students also pointed out in their feedback that classmates as feedback providers were an essential element of our case study. In connection to classmates as feedback providers, it was emphasised that classmates were consulted both when problems were acute and when feedback on new strategies or ideas for solving the problem was needed.

[I, b-b] Working or learning in a group is really great. We only argue from time to time how we will implement our ideas. Do not think about it, it is quite normal for us.

[F] It was good that in a first step you could immediately ask your seat neighbour if you did not understand something.

In addition to feedback on concrete strategies or ideas for solving the mathematicallogical problem of our case study, it was vital to students that the learning goal and task communication were clear and that questions concerning learning goal or task could be asked at any time.

[I, g-g-g] It was really good that you explained at the beginning exactly what we should do - and thank you that we can ask you again because we do not know all the details.

[F] If the task and the images related to the task would have remained visible on the beamer for the whole lesson, that would have helped. But as we could always ask you, it was not that bad.

However, not only the teacher or classmates were described by the students as feedback instruments. Also Logifaces-stones and Excel could be used to test developed strategies for solving the mathematical-logical problem was described by the students as a means of feedback.

[I, b-b] Experimenting with the stones and the program is cool - and you can immediately check if the program is correct.

In summary, feedback for students is a key design element in our exploratory educational study. The decisive aspect for the students in our study was, on the one hand, that they could choose from a variety of feedback options. On the other hand, the feedback from the students made it evident that regardless of the type of feedback, it was important for the students that the desired feedback medium was available immediately when questions or problems arose. Thus, not only just-in-time learning but also just-intime feedback was a central design element for the students of our exploratory educational study.

\subsection{Novelty effects in the learning process}

Students' feedback made it clear that what was new or different in our exploratory educational study was a key design element for the students in our study. Students often described the new or different in our study in an undifferentiated way, merely contrasting the new or different with everyday teaching. 
[I, b-b] Today it is a real change compared to normal lessons - that is exciting.

[F] What I liked about working with Logifaces was that it was really creative and different learning than usual.

However, much of students' feedback also related to concrete design elements of our study. An essential aspect for the students was combining mathematics learning as well as using Logifaces-stones and technologies. The surprise associated with this combination had a positive effect on the students' motivation, which can be found in the teaching notes as well as in the written feedback from the students:

[F] I found working with the building blocks really interesting and I would not have thought at first that the building blocks could have anything to do with mathematics or information.

In addition to combining mathematics, Logifaces-stones and technologies, new insights into the potential uses of Excel were a design element of our study that was remarkable for students.

[I, b-b-b] These lessons reveal just how powerful Excel actually is ... I would not have thought that you can almost do coding with Excel.

The feedback revealed that learning in our case study was always exciting and therefore motivating for students when something new or unexpected occurred during the learning process. This new or unexpected could refer to the design as a whole or very specific elements of our exploratory educational case study.

\section{Discussion}

In our explorative educational case study, examining how real-world objects and technologies could be combined in mathematics learning, the analysis of students' feedback indicated that key design elements in the learning process were A) using open tasks with multiple solutions, B) just-in-time feedback, and C) novelty effects .

The importance of using multi-step open tasks to improve the quality of mathematics teaching has already been identified by Carreira and Baioa (2018) and Heck (2010). Following Carreira and Baioa (2018), real-world problems, and therefore problems that are open-ended and allow multiple solutions, should lead to students using school and nonschool knowledge and competencies in solving these tasks in mathematics lessons. Heck (2010) emphasises that one of the advantages of using real-world problems is that students learn like scientists when dealing with such problems. Also, treating open tasks with multiple solutions could be described as learning and researching like real scientists. Results of our study add to these findings dealing with real-world or open-ended problems with multiple solutions could improve not only the quality of mathematics teaching but also the motivation of students. Findings of Noss and Hoyles (2010) and Noss et al. (1997) suggest that learning environments could be developed into laboratories by using technologies. In such environments, mathematical content could be explored experimentally and creatively following the feedback from students in our exploratory educational study. 
Furthermore, according to students' feedback, it could be concluded that this learning environment could increase students' motivation, which, in turn, should have a positive effect on students' learning outcomes.

Similar to Tabach et al. (2006), students in our exploratory educational study showed considerable cognitive gains in learning logical operations according to their feedback. If students are to achieve significant cognitive gains in open and real-world problem-based learning environments, it was important for students in our study to receive continuous feedback on their problem-solving strategies and help when the learning process has stalled; feedback on solution strategies concerned using technologies and real-world objects. Using technologies and real-world objects as feedback tools means, following the feedback of the students of our study, that the developed Excel program and the Logifaces-stones were used to examine if the logical operations were used correctly. Furthermore, it was also essential for students of our study to get personal feedback. The personal feedback included feedback from the teacher as well as feedback from classmates. This high demand for personal feedback from the students in our study confirms the results of Clarkson (2003) that learning logical operators and the associated communication regarding logical operators could also improve the students' language skills.

The importance of novelty effects in the learning process for the students in our study extends the findings of Carreira and Baioa (2018) and Heck (2010) as well as Noss and Hoyles (2010) and Noss et al. (1997). For students in our study, it was essential to be able to learn with real-world problems like a real scientist (Carreira and Baioa 2018; Heck 2010) and to expand knowledge experimentally and creatively in laboratory-like learning environments (Noss and Hoyles 2010; Noss et al. 1997). It was equally important to students that new and unexpected insights could be gained during these learning processes.

Analysing feedback from students in our exploratory educational study highlighted the importance for students of addressing real-world and open problems in class. In dealing with these real-world and open problems, students wanted to be able to use their ideas and strategies, and experiment with these ideas and strategies. In order to facilitate experimentation with their ideas, it could be fruitful to combine technological and real-world object-based learning environments. When experimenting with their ideas and using self-developed strategies, the students of our study were motivated by the fact that they not only gained insights that could have been gained in a teachercentred classroom. Students of our study emphasised that it was central to them that new and unexpected things could be discovered while learning. In order to discover new and unexpected things, it was vital for the students of our study that they had confidence in the learning process. In order to have confidence in the learning process, it was important for the students of our exploratory educational study to be able to receive feedback when needed. This feedback could be either personal or technology based.

\section{Conclusion and implications for education}

To find out which design elements are essential for students to learn basic logical skills in a learning environment where real-world objects and technologies are linked, we 
conducted an exploratory educational study. Analysing students' feedback demonstrated that using open tasks with multiple solutions, just-in-time feedback and novelty effects in the learning process was key for students in our study. In this context, it was interesting to note that those activities that were cognitively most challenging were most often positively mentioned by the students. It was the 'puzzling around' and experimenting, which was described by the students as particularly motivating elements of our study. In this puzzling around or experimenting with their solution strategies, it was also crucial for the students in our study that new or unexpected things could be discovered in these challenging processes. According to these results of our exploratory educational study, essential design elements of a productive mathematics learning environment are that students have challenging tasks to solve in the course of which new and, above all, unexpected things can be discovered. To ensure that the learning process in such environments is not overstrained, it was crucial for the students of our study that there is a rich repository of feedback possibilities. What was interesting in terms of feedback possibilities was that using technologies and the associated testing of solutions was described by the students as feedback. This possibility of using technologies could also be helpful in other mathematics learning settings and could increase students' confidence in mathematics learning, as well as accessible to a wider and/or different skill set of teachers, for example by moving the feedback task further from teacher to technology.

Challenging and demanding tasks in combination with real-world objects and technologies as well as the provision of personal and technological feedback make it evident that the designers and implementers of such learning settings should currently be highly qualified. Designers and implementers of such learning settings are usually only one person - the teacher. To be able to use the potential of a mathematics learning environment based on real-world tasks, real-world objects and technologies in the best possible way, highly trained teachers are required.

Specific tasks and requirements for such teachers in a learning environment such as in our exploratory educational study were not investigated in this study but will be the focus of our next research step. It is the intention that this will allow us to identify teacher training requirements and also how or if certain tasks e.g. feedback, may be flexibly allocated between teacher and technology making the learning environment accessible to a wider and/or different skill set of teachers.

Acknowledgements At this point we would like to thank the teachers and the management of the Akademisches Gymnasium Wien, who made our case study possible. A special thanks goes to Alexander Kandl and Katharina Krebs from the management as well as to Michael Molnar and the teaching team.

Authors' contributions Not applicable.

Funding Information Open access funding provided by Johannes Kepler University Linz.

Data availability Extracts from the data collected and analysed are included in the text. Please inform us if you want us to transmit the complete data set and code book. 


\title{
Compliance with ethical standards
}

\author{
Conflict of interest Not applicable.
}

Code availability Not applicable.

Open Access This article is licensed under a Creative Commons Attribution 4.0 International License, which permits use, sharing, adaptation, distribution and reproduction in any medium or format, as long as you give appropriate credit to the original author(s) and the source, provide a link to the Creative Commons licence, and indicate if changes were made. The images or other third party material in this article are included in the article's Creative Commons licence, unless indicated otherwise in a credit line to the material. If material is not included in the article's Creative Commons licence and your intended use is not permitted by statutory regulation or exceeds the permitted use, you will need to obtain permission directly from the copyright holder. To view a copy of this licence, visit http://creativecommons.org/licenses/by/4.0/.

\section{References}

Bakker, A., \& van Eerde, D. (2015). An introduction to design-based research with an example from statistics education. In A. Bikner-Ahsbahs, C. Knipping, \& N. Presmeg (Eds.), Approaches to qualitative research in mathematics education: examples of methodology and methods (pp. 429-466). Springer Netherlands. https://doi.org/10.1007/978-94-017-9181-6_16.

Borba, M. C., Askar, P., Engelbrecht, J., Gadanidis, G., Llinares, S., \& Aguilar, M. S. (2016). Blended learning, e-learning and mobile learning in mathematics education. ZDM, 48(5), 589-610.

Breuer, F., Dieris, B., \& Lettau, A. (2009). Reflexive grounded theory: Eine Einführung für die Forschungspraxis (2009th ed.). Wiesbaden: VS Verlag für Sozialwissenschaften.

Carreira, S., \& Baioa, A. M. (2018). Mathematical modelling with hands-on experimental tasks: On the student's sense of credibility. ZDM, 50(1), 201-215. https://doi.org/10.1007/s11858-017-0905-1.

Celedón-Pattichis, S., LópezLeiva, C. A., Pattichis, M. S., \& Llamocca, D. (2013). An interdisciplinary collaboration between computer engineering and mathematics/bilingual education to develop a curriculum for underrepresented middle school students. Cultural Studies of Science Education, 8(4), 873-887.

Charmaz, K. (2006). Constructing grounded theory: A practical guide through qualitative analysis (1st ed.). London: SAGE Publications Ltd.

Clarkson, P. C. (2003). Language, logical thinking and communication in school mathematics: Whose responsibility. InStudies in science, mathematics and technical education (pp. 99-116).

Cobb, P. (1986). Concrete can be abstract: A case study. Educational Studies in Mathematics, 17(1), 37-48. https://doi.org/10.1007/BF00302377.

Cohen, L., Manion, L., \& Morrison, K. (2007). Research methods in education (Sixth ed.). London: Routledge.

Eynde, P. O., \& Hannula, M. S. (2006). The case study of frank. Educational Studies in Mathematics, 63(2), 123-129. https://doi.org/10.1007/s10649-006-9030-8.

Heck, A. (2010). Modelling in cross-disciplinary authentic student research projects. International Journal for Technology in Mathematics Education, 17(3), 115-120.

Henderson, P. B. (2014). Pre-college computing math. ACM Inroads, 5(3), 40-41.

Kabaca, T. (2013). Using dynamic mathematics software to teach one-variable inequalities by the view of semiotic registers. Eurasia Journal of Mathematics, Science \& Technology Education, 9(1), 73-81.

Kane, T. J., \& Staiger, D. O. (2012). Gathering feedback for teaching: Combining high-quality observations with student surveys and achievement gains. Research Paper. MET Project. Bill \& Melinda Gates Foundation.

Khan, S. N. (2014). Qualitative research method: Grounded theory. International Journal of Business and Management, 9(11). Published by Canadian Center of Science and Education. https://doi.org/10.5539 /ijbm.v9n11p224.

Mey, G., \& Mruck, K. (2011). Grounded theory reader (2nd ed.). Wiesbaden: VS Verlag für Sozialwissenschaften. 
Niss, M., \& Højgaard, T. (2019). Mathematical competencies revisited. Educational Studies in Mathematics, 102(1), 9-28. https://doi.org/10.1007/s10649-019-09903-9.

Noss, R., \& Hoyles, C. (2010). Modeling to address techno-mathematical literacies in work. InModeling students' mathematical modeling competencies (pp. 75-86). Springer.

Noss, R., Healy, L., \& Hoyles, C. (1997). The construction of mathematical meanings: Connecting the visual with the symbolic. Educational Studies in Mathematics, 33(2), 203-233.

OECD. (2015). PISA-2015-Datenbanken. https://doi.org/10.1787/888933432735.

Pierce, R., \& Stacey, K. (2011). Using dynamic geometry to bring the real world into the classroom. In L. Bu \& R. Schoen (Eds.), Model-centered learning: Pathways to mathematical understanding using GeoGebra (pp. 41-55). SensePublishers. https://doi.org/10.1007/978-94-6091-618-2 4.

Ritchie, S. (2012). Incubating and sustaining: How teacher networks enable and support social justice education. Journal of Teacher Education, 63(2), 120-131. https://doi.org/10.1177/0022487111428327.

Samuelsson, J. (2006). ICT as a change agent of mathematics teaching in Swedish secondary school. Education and Information Technologies, 11(1), 71-81. https://doi.org/10.1007/s10639-005-5713-5.

Tabach, M., Hershkowitz, R., \& Schwarz, B. (2006). Constructing and consolidating of algebraic knowledge within dyadic processes: A case study. Educational Studies in Mathematics, 63(3), 235-258. https://doi. org/10.1007/s10649-005-9012-2.

Yin, R. K. (1984). Case study research: Design and methods. Newbury Park: Sage.

\section{Links to the curricula}

https://friedolin.uni-jena.de/qisserver/rds;jsessionid=D6FF041661EAC277A63205E55219A71A.worker32 ?state=wtree \&search=1\&root120192=473737\%7C472876\%7C472594\%7C472149\%7C472583\&trex= step. 11.02.2020.

https://online.fh-wien.ac.at/fhwienonline/wbLv.wbShowLVDetail?pStpSpNr=230291\&pSpracheNr=. 11.02.2020.

https://hpsg.hu-berlin.de/ stefan/Lehre/S2012/as-logik.html. 11.02.2020.

Publisher's note Springer Nature remains neutral with regard to jurisdictional claims in published maps and institutional affiliations. 